\title{
Antagonistic interactions among cultivable actinomycetes isolated from agricultural soil amended with organic residues
}

\author{
Sonia Mokni-Tlili, Naceur Jedidi and Abdennaceur Hassen \\ Laboratoire de Traitement et Recyclage des Eaux Usées, Centre des Recherches et des Technologies des Eaux, \\ Technopole de Borj Cedria, BP 273, Soliman 8020-Tunisie.
}

Accepted 23 August, 2011

\begin{abstract}
The present work focuses on the antagonistic interactions among cultivable actinomycetes isolated from agricultural soil and organic amendments (farmyard manure and municipal solid waste compost). Antagonistic interactions, assayed by the double-layer agar method, were checked among isolates obtained from (i) the same treatment (ii) control soil (unamended) against those from amendments and (iii) each treatment against tow phytopatogenic bacteria (Agrobacterium tumefaciens B6 and C58). A high suppressive interaction ratio $(\geq 50 \%)$ was registered some either the treatment soil. It was found that amendments application decreased this suppressive interaction ratio between actinomycetales. But, it increases the ratio of the antagonistic actinomycetales from soil against Agrobacterium tumefaciens confirming the role of these organic residues as fertilizers. It was also shown, based on the phylogenetic affiliation of bacteria, that the antagonism can play a significant role in structuring bacterial communities in soil.
\end{abstract}

Key words: Antagonism, Actinomycetales, agricultural soil, manure, compost.

\section{INTRODUCTION}

Because of their important role on the ecosystem, numerous ecological studies of actinomycetale were conducted in marine habitats: beach sands (Suzuki et al., 1994), sub-glacial ice of Antarctica (Priscu et al., 1999), underground caves (Groth et al., 1999), Antarctic marine sponge (Mangano et al., 2009); agricultural habitats: orchards (Lee and Hwang, 2002), grasslands (Lee and Hwang, 2002), rice-paddies (Hayakawa et al., 1988), rhizosphere (Gesheva, 2002), tomato plants (Fialho de Oliveira et al., 2010), composted Eucalyptus bark (Hardy and Sivasithamparam, 1995), forest soils (Jayasinghe and Parkinson, 2008) and wastewater treatment (Bensultana et al., 2010). It was shown that actinomycetales constitute a significant component of the microbial population in each environment, especially in soil. They are a main member of soil decomposer community; they play an important role in recycling complex organic materials such as lignocelluloses and chitin (Epstein, 1997; Li et al., 2010; Tiquia et al., 2002).

In previous works on the effect of organic amendments application to agricultural soil on the distribution of the actinomycetales community, it was shown that the bacteriological and physico-chemical composition of amendments strongly affect the bacterial diversity. This was either by contribution, stimulation or inhibition (Mokni-Tlili et al., 2011a). Nevertheless, other phenolmena can involve on the community structure of bacteria. The antagonism is one of the most important phenomena as shown by several workers (Grossart al., 2004; Hentschel et al., 2001; Lo Giudice et al., 2007; Long and Azam, 2001; Mangano et al., 2009). The interactions among bacteria inhabiting the same niche represent an in- 
interesting evolutionary strategy, conferring a selective advantage in competition for nutrients and space in the environment and acting as an effective control of microbial populations (Hentschel et al., 2001). Moreover, it was suggested that the antagonistic effect, studied for phylogenetically different bacterial groups, is a widespread trait in several habitats (Bhattarai et al., 2006; Grossart et al., 2004; Long and Azam, 2001).

On the other hand, bacteria interactions can result on the production of biocontrol agents by microorganisms. These agents can play a primordial role in reducing pesticide use in the treatment of phytopathogenic diseases (Fialho de Oliveira et al., 2010), knowing that agrochemical treatment may result in environmental impact and pose a threat to humans and animals. Actinomycetales have been considered among potential biocontrol agents for plant diseases producing antibiotic (Igarashi, 2004) and enzymes such as cellulases, hemicellulases, chitinases, amylases, and glucanases (Mokni-Tlili et al., 2010; 2011b; Yuan and Crawford, 1995).

The present work aims mainly to better understand the effect of organic amendments application on the diversity of actinomycetes in agricultural soil through an antagonistic interactions study. Amendments were farmyard manure (FM) and municipal solid waste compost (MSWC). Antagonistic interactions were performed among isolates obtained (i) from the same treatment (ii) from control soil (unamended) against those isolated from amendments and (iii) from each treatment against tow phytopatogenic bacteria (Agrobacterium tumefaciens B6 and C58) using the double-layer agar method.

\section{MATERIALS AND METHODS}

\section{Actinomycetales collection}

Studied bacteria are actinomycetes already isolated from soil untreated and treated with farmyard manure (FM) and municipal solid waste compost (MSWC). Soil samples were collected from an open field in the experimental farm of the Agronomic National Institute of Tunis (INAT). The field is located in northern Tunisia and belongs to the semi-arid superior bioclimatic stage (Mokni-Tlili et al., 2009). We recall here briefly that soil, which has a clayey-loamy texture, was treated with MSWC applied at $40 \mathrm{tha}^{-1}$ (C40), $80 \mathrm{t} \mathrm{ha}^{-1}$ (C80), $120 \mathrm{t} \mathrm{ha}^{-1}$ (C120), FM at $40 \mathrm{t} \mathrm{ha}^{-1}$ (F40) and $120 \mathrm{t} \mathrm{ha}^{-1}$ (F120), respectively. The main physicochemical characteristics of soil and amendments were reported previously in Mokni-Tlili et al. (2011a).

The isolation, enumeration and identification of actinomycetes were based on a morphological and a molecular study using PCR amplification and restriction analysis of 16S rRNA genes from bacterial isolates (Amplified rDNA Restriction Analysis, or ARDRA; Vaneechoutte et al., 1992). On the basis of restriction patterns obtained, the isolates were clustered into Operational Taxonomic Units (OTUs), assuming that each OTU (assigned to a number) included strains belonging to the same species. For each OTU, one to three representative strains showing the identical ARDRA pattern were randomly selected for $16 \mathrm{~S}$ rDNA sequencing. Each sequence was then used as a query in a BLASTn (Altschul et al., 1997) search and further aligned to the most similar sequences retrieved from the database using the program ClustalW (Thompson et al., 1994). The representative bacteria sequences of the actinomycetales collection, composed of 281 isolates, were submitted to GenBank and assigned the following accession numbers: FJ941916 to FJ941954. This was shown three dominant Actinomycetales families: Streptomycetaceae (72\%), Pseudonocardiaceae (23\%) and Nocardioidaceae (5\%) (Table 1).

In the present work, the three families (Streptomycetaceae represent the majority of tested bacteria) were considered for the antagonism tests (i) among bacteria from the same treatment (20 isolates from each soil treatment) and (ii) among bacteria from untreated soil against those from amendments $(20,17$ and 35 isolates from soil T, MSWC and FM, respectively).

Screening for antagonistic interactions among bacterial isolates

To evaluate the antimicrobial activity, all isolates were screened for antagonistic interactions. For this, bacteria were spot-inoculated onto SCA medium - composed of $10.0 \mathrm{~g}$ starch, $0.3 \mathrm{~g}$ casein, $2.0 \mathrm{~g}$ $\mathrm{K}_{2} \mathrm{HPO}_{4}, 2.0 \mathrm{~g} \mathrm{NaCl}, 2.0 \mathrm{~g} \mathrm{KNO}_{3}, 0.05 \mathrm{~g} \mathrm{MgSO}_{4}, 7 \mathrm{H}_{2} \mathrm{O}, 0.01 \mathrm{~g}$ $\mathrm{Fe}_{2}(\mathrm{SO} 4)_{3} .6 \mathrm{H}_{2} \mathrm{O}$ and $15.0 \mathrm{~g}$ agar - and incubated at $30^{\circ} \mathrm{C}$ for 14 days. Then, the antagonism between bacteria was evaluated using the double-layer agar method. It consists to add $10 \mathrm{ml}$ MuellerHinton overlay agar medium inoculated with $10^{6}$ spores $/ \mathrm{ml}$ of isolate. All plates were incubated at $30^{\circ} \mathrm{C}$ during 48 to $72 \mathrm{~h}$. All experiments were carried out in duplicate. Hereafter, bacterial isolates tested for inhibitory activity will be termed "tester" strains, whereas those used as targets will be called "target" strains. Tester strains were streaked on SCA medium and the target strains were inoculated in Mueller-Hinton overlay agar medium.

The antagonistic effect was indicated by failure of the target strain to grow in the confluence area. Bacterial isolates were then operationally distinguished into three different interactivity clusters, termed: (1) active, if they were able to inhibit growth of at least one bacterial target; (2) sensitive, if their growth was inhibited by at least one isolate used as a tester; and (3) resistant if their growth was never inhibited by tester strains. It must be noted that an individual strain could be included in one or two interactivity clusters.

Screening for antagonistic interactions against tow phytopathogen bacteria

Antagonism test was performed as above. The Mueller-Hinton overlay agar medium was added and inoculated with $10^{9}$ cells $/ \mathrm{ml}$ of target bacteria: A. tumefaciens B6 and C58. All plates were incubated at $30^{\circ} \mathrm{C}$ during $24 \mathrm{~h}$ and experiments were carried out in duplicate.

\section{RESULTS AND DISCUSSION}

\section{Antagonistic interaction among bacteria isolated from the same treatment}

Figure 1 represents the inhibitory interaction ratio among bacteria obtained from each soil treatment and amendments. It shows that the active isolates varied between 50 to $95 \%$ of the total bacteria number. The highest rate of producer strains, registered in all treatments, can be attributed to the bioactive secondary metabolites synthesis, known propriety for actinomycetes 
Table 1. 16S rRNA gene sequence affiliation, with their closest phylogenetic neighbors, of soil bacterial isolates representing each OTU obtained by ARDRA.

\begin{tabular}{|c|c|c|c|c|c|c|c|c|c|c|}
\hline Phylogenetic group & OTU & Soil T & Soil F & Soil C & FM & MSWC & $\begin{array}{c}\text { Representative } \\
\text { isolate }\end{array}$ & $\begin{array}{c}\text { Accession } \\
\text { number }\end{array}$ & Most related species & $\begin{array}{c}\text { Sequence } \\
\text { homology (\%) }\end{array}$ \\
\hline & 7 & 4 & 3 & - & - & - & $\mathrm{T} 1$ & FJ941954 & EF063499, S. venezuelae & 99 \\
\hline & 14 & 8 & 5 & - & 1 & - & $\mathrm{T} 2$ & FJ941922 & DQ026634, S. globisporus subsp. globis. & 99 \\
\hline & 48 & 17 & 12 & 15 & 4 & - & T3 & FJ941923 & AB249953, S. albidochromogenes & 99 \\
\hline & 1 & 1 & - & - & - & - & $\mathrm{T} 5$ & FJ941929 & AB249935, S. flavofuscus & 99 \\
\hline & 1 & 1 & - & - & - & - & T8 & FJ941936 & AB184157, S. narbonensis & 99 \\
\hline & 19 & 10 & 9 & - & - & - & T9 & FJ941938 & AB249921, S. spiroverticillatus & 99 \\
\hline & 13 & 8 & 5 & - & - & - & $\mathrm{T} 10$ & FJ941937 & DQ026647, S. exfoliatus & 99 \\
\hline & 7 & - & 6 & - & 1 & - & M1 & FJ941916 & DQ026670, S. clavifer & 99 \\
\hline & 1 & - & 1 & - & - & - & M2 & FJ941917 & AB184068, S. fradiae & 99 \\
\hline & 1 & - & 1 & - & - & - & M3 & FJ941953 & DQ487016, S. sp. B267 & 98 \\
\hline & 7 & - & 7 & - & - & - & M4 & FJ941918 & AJ308577, S. sp. Nm5 & 99 \\
\hline & 9 & - & 7 & - & 2 & - & M5 & FJ941920 & AB184800, S. coelicolor & 99 \\
\hline & 9 & - & 8 & - & 1 & - & M6 & FJ941921 & DQ663179, S. sp. 3004 & 98 \\
\hline & 1 & - & 1 & - & - & - & M7 & FJ941926 & $\mathrm{EF} 119843$, S. sp. AHW3 & 98 \\
\hline & 20 & - & 6 & 13 & 1 & - & M9 & FJ941931 & EF063493, S. sp. P3562 & 98 \\
\hline & 17 & - & 1 & 12 & 1 & 3 & $\mathrm{C} 1$ & FJ941919 & AB184220, S. longisporoflavus & 99 \\
\hline \multirow[t]{13}{*}{ Streptomycetaceae } & 1 & - & - & 1 & - & - & C3 & FJ941925 & DQ026671, S. cavourensis subsp. Wash. & 99 \\
\hline & 4 & - & 3 & 1 & - & - & $\mathrm{C} 22$ & FJ941930 & DQ250003, S. sp. L42 & 98 \\
\hline & 3 & - & - & - & 3 & - & FM3 & FJ941946 & DQ445791, S. cavourensis subsp. C. & 100 \\
\hline & 5 & - & - & - & 5 & - & FM5 & FJ941947 & AY999837, S. californicus & 100 \\
\hline & 2 & - & - & - & - & 2 & MSWC1 & FJ791059 & EF371429, S. aureus & 99 \\
\hline & 3 & - & - & - & 1 & 2 & MSWC2 & FJ941949 & EU257256, S. sp. A528 & 99 \\
\hline & 3 & - & - & - & 2 & 1 & MSWC3 & FJ941945 & EU273552, S. collinus & 100 \\
\hline & 6 & - & - & - & 2 & 4 & MSWC5 & FJ941942 & AF306660, S. sacchari & 99 \\
\hline & 4 & - & - & - & 2 & 2 & MSWC8 & FJ941951 & AF026081, S. sp. CHR28 & 99 \\
\hline & 2 & - & - & - & 1 & 1 & MSWC9 & FJ941952 & DQ086264, S. sp. AB654 & 99 \\
\hline & 1 & - & - & - & - & 1 & MSWC11 & FJ941940 & AB184676, S. griseoaurantiacus & 99 \\
\hline & 1 & - & - & - & - & 1 & MSWC12 & FJ941941 & EF178674, S. azureus & 100 \\
\hline & 15 & - & 9 & - & 6 & - & M8 & FJ941928 & AF005005, Nocardioides albus & 98 \\
\hline Nocardioidaceae & 2 & - & - & - & 2 & - & FM9 & FJ941939 & EU284126, Amycolatopsis sp. WX001 & 99 \\
\hline \multirow{2}{*}{ Pseudonocardiaceae } & 20 & 13 & 7 & - & - & - & $\mathrm{T7}$ & FJ941934 & AY561610, Actinobacterium RG-51 & 98 \\
\hline & 1 & - & 1 & - & - & - & M11 & FJ941935 & DQ125918, Uncultured bacterium & 99 \\
\hline Unidentified & 33 & 10 & 7 & 13 & 2 & 1 & & & & \\
\hline
\end{tabular}

${ }^{\text {a }}$ Accession number of isolates.

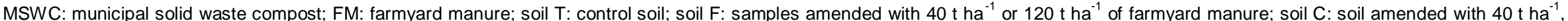
$80 \mathrm{t} \mathrm{ha}^{-1}$ or $120 \mathrm{t} \mathrm{ha}^{-1}$ of MSWC. 


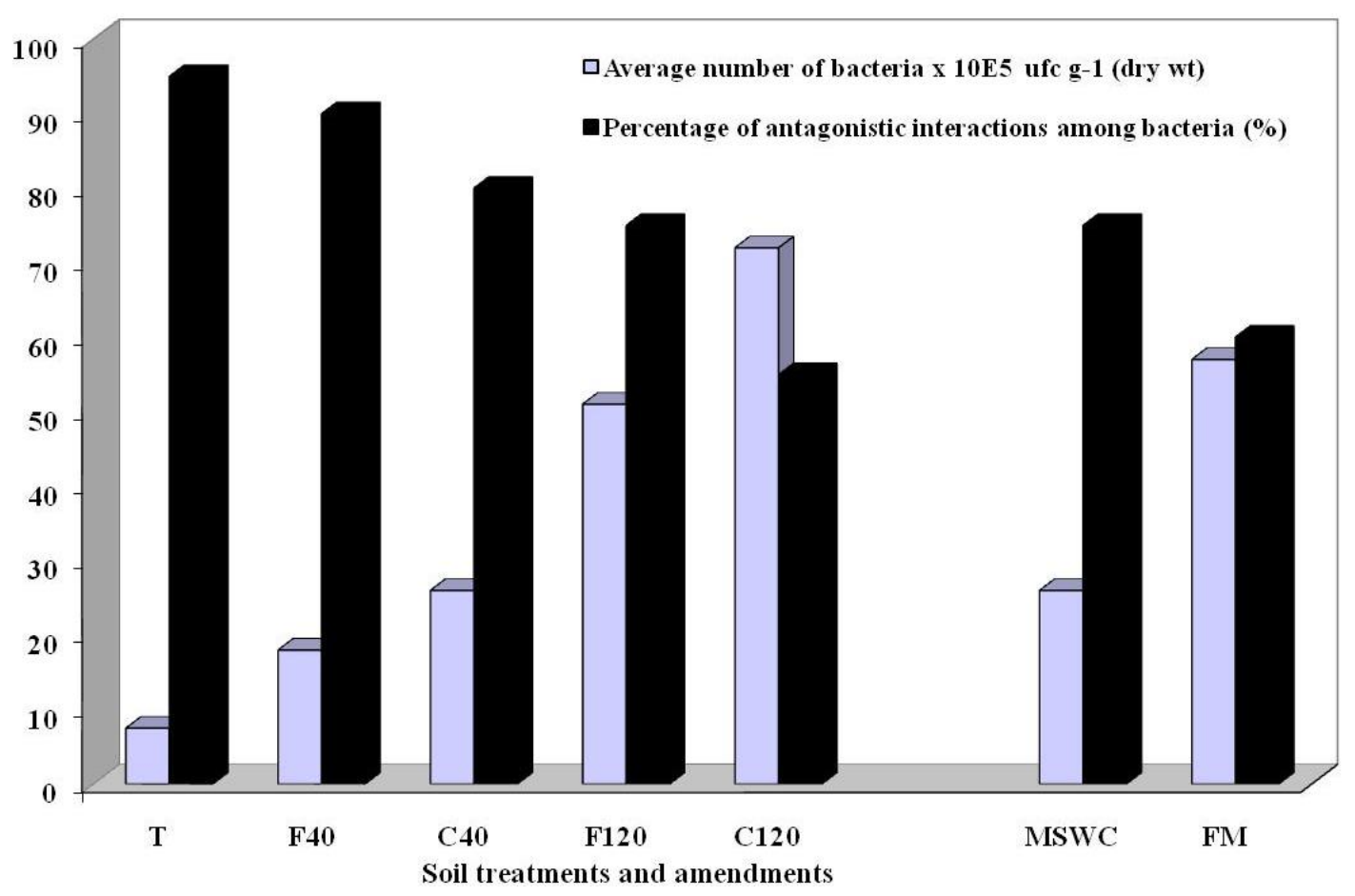

Figure 1. Plate counts (ufc $\mathrm{g}^{-1}$ dry weight) of Actinomycetales content in soil and percentage of antagonistic interactions among tested isolates according to the type of amendment

originated from environment (Duraipandiyan et al., 2010; Fialho de Oliveira et al., 2010; Fourati-Ben Fguira et al., 2005; Mangano et al., 2009). Indeed, they produce about $75 \%$ of commercially and medically useful antibiotics (Miyadoh, 1993) and approximately $60 \%$ of antibiotics which have been developed for agricultural use (Tanaka and Mura, 1993).

On the other hand, it was clearly shown that amendments strongly affect the bacteria behavior regarding the suppressive interactions between studied isolates. The higher antagonistic interaction rate, registered for control soil $\mathrm{T}(95 \%)$, decreases with amendment application. This effect depends not only on the amendment nature but also on its applied amount. e.g. for treated soil with $\mathrm{FM}$, the active isolates rate decreases to 90 and 75 when it was applied at 40 (F40) and 120 t/ha of FM (F120), respectively. This decrease can reach lower values, for the same applied amount, about $55 \%$ (C120) in the case of MSWC application (120 t/ha). This can be explained based on the physico-chemical analyses which show that amendments are richer in nutrient (carbon, nitrogen and organic matter) than soil T (Mokni-Tlili et al., 2011a). Indeed, the stress due to the shortage of nutrients can activate the metabolic mechanisms for microorganisms as founded by several workers (Celar, 2003; Lumsden et al., 1990; Meidute et al., 2008). Especially, for the study elaborated by Celar (2003) on the competition for nitrogen forms between some phytopathogenic and antagonistic soil fungi, where it was shown that nutrients have a direct and indirect influence on growth, morphogenesis, and organogenesis of antagonistic.

However, amendments can stimulate the antagonistic interactions. Indeed, previous works show that the addition of organic matter stimulates the activities of microorganisms such as actinomycetes (Mokni-Tlili et al., 2011b), bacteria, fungi, algae, and other (Akhtar and Malik, 2000) by enhancing their enzymatic synthesis. Seeing that the amendment application play a double opposite roles by decreasing the stress in nutriments and then the antagonism and by enhancing the enzymatic synthesis and then stimulate the antagonism, it seems that the first effect outweighs the last one for the present study. Knowing that FM is richer in nutrient than MSWC, this above discussion is not suitable to explain obtained results for amended soil where the antagonistic interactions are more important in soil $F$ than soil C (e.g. F120: 75 and $\mathrm{C} 120$ : $55 \%$ of antagonists bacteria). This shows that the effect of the other chemical composition, apart the nutriments, of the amendments must not be neglected. Indeed, MSWC presents the particularity to be richer in heavy metals $\left(\mathrm{Cu}^{2+}: 337 \mathrm{mg} \mathrm{kg}^{-1}, \mathrm{Zn}^{2+}: 290.25 \mathrm{mg} \mathrm{kg}^{-}\right.$ ${ }_{1}, \mathrm{Ni}^{2+}: 90.8 \mathrm{mg} \mathrm{kg}^{-1}, \mathrm{Cr}^{3+}: 78.9 \mathrm{mg} \mathrm{kg}{ }^{-1}, \mathrm{~Pb}^{2+}: 80.1 \mathrm{mg}$ $\left.\mathrm{kg}^{-1}\right)$. It was reported that such elements are toxic and can decreases the bacterial activity (Mokni-Tlili et al., 2010; Rajapaksha et al., 2004; Tobor-Kaplon et al., 2005).

In Figure 1, the superposition of antagonism and numbering results shows that the antagonistic bacteria ratio 

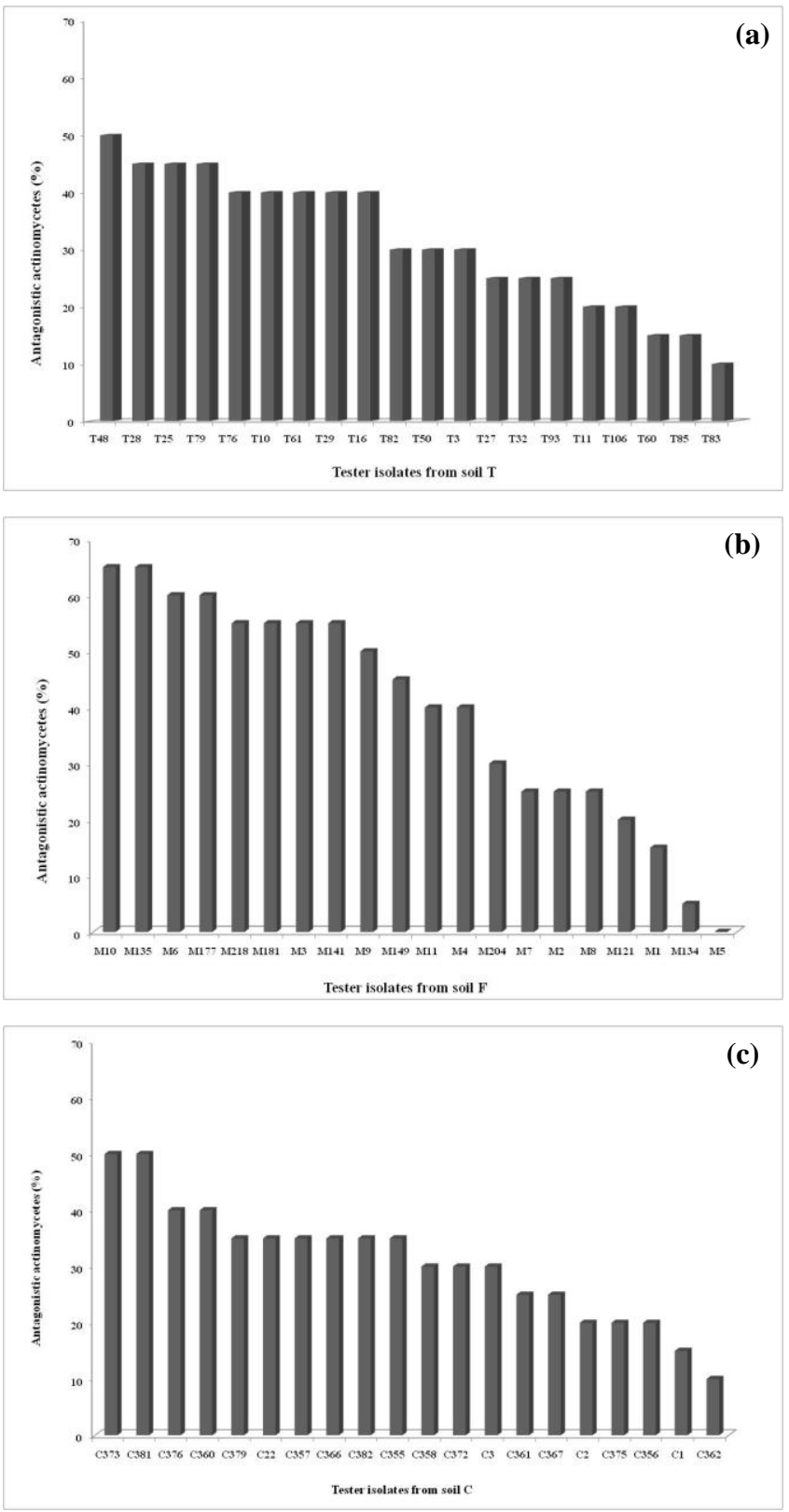

Figure 2. Antagonistic interactions among actinomycetales isolated from control soil (a), soil F (b) and soil C (c)

increases inversely with the number of bacteria in ufc $\mathrm{g}^{-1}$ dry matter of soil. This increase of bacteria number in amended soil was previously attributed to the amendment contribution of bacteria and nutriments, which stimulate the bacteria of control soil (Mokni-Tlili et al., 2011a). Now, from founded results (Figure 1), it can be suggested that the antagonistic activities play also a primordial role. Indeed, amendments application inhibits the suppressive interactions.

Other workers which were interested on bacteria originnated from the rhizosphere soil of Citrus (Gesheva, 2002) and from the Antarctic sponges (Mangano et al., 2009), showed contradictory results: the bacteria number increases with the antagonistic activities. In the case of the rhizosphere soil of Citrus, the more loaded with Streptomyces: C. sinensis: $87 \%$ (against C. limon: $52 \%$ ) presents the high rate of antagonistic actinomycetes: $72 \%$ of antagonistic cultures (against $43 \%$ for C. limon). The Antarctic sponge containing more loaded with cultivable bacteria: Anoxycalyx joubini: $5.210^{5}$ cfu per gram of sponge tissues (against Lissodendoryx nobilis: $1.810^{5}$ ) presents the high percentage of antagonistic bacteria: $90 \%$ (against L. nobilis: $62 \%$ ). Therefore, this can shows that bacteria-origin is an important parameter on the antagonistic potentiality.

For more detail and specificity, antagonistic results were re-treated to show the percentage of active isolates against each target bacteria in each treatment. e.g. Figure 2 shows the results for isolates originated from soils $T, F(F 40)$ and $C(C 120)$. These histograms show that the sensitive isolates increase with amendments application, especially for FM. For example, considering the 20 tested strains originated from each treatment, it was founded that 9 strains are sensitive to more than $50 \%$ for soil $\mathrm{F}$ against 2 and only one strain for soils $\mathrm{C}$ and $\mathrm{T}$, respectively. On the other hand, it could be noted that the most sensitive (M10 and M135 isolated from F40 and affiliated to Streptomyces spectabilis and Sreptomyces coelicolor, respectively) and resistant (M5: isolated from F40 and affiliated to S. coelicolor and M285: isolated from F120 and affiliated to Nocardioides albus) strains are founded in soil $F$ (Table 2). Then, soil $F$ presents more heterogeneity in inhibition patterns and rate than soil $T$ and soil $C$. This can be attributed to the effect of FM on the bacteria diversity. Indeed, it was previously shown that FM application increases more the phylogenetically difference in soil than the MSWC (Mokni-Tlili et al., 2011a).

\section{Relation between diversity and antagonistic potential}

Tables 2 and 3 show the inhibitory activities and susceptibility of some isolates in relation to their phylogenetic affiliation following individual antagonistic tests. It was observed that the inhibition patterns varied for different bacterial isolates (Table 3), even if they were grouped in the same OTU and even belonging to the same species (e.g. M5, M135 and M204 affiliated to S. coelicolor) (Table 2). This finding was observed in all treatments and amendments (data not shown) and suggests that antagonism might be due to different inhibitory mechanisms within the same species. However, although possible, inhibitory interactions were rarely detected among isolates belonging to the same OTU (e.g. M141 and M181 affiliated to Streptomyces longisporoflavus) (Tables 2 and 3). This can be supported by the founded results of Grossart et al. (2004); Lo Giudice et al. (2007); Long and Azam (2001); Mangano et al. (2009). From 
Table 2. Antagonistic interactions among bacteria isolated from soil $F(F 40)$.

\begin{tabular}{|c|c|c|c|c|c|c|c|c|c|c|c|c|c|c|c|c|c|c|c|c|}
\hline \multirow{2}{*}{ Tester strain } & \multicolumn{20}{|c|}{ Target strain } \\
\hline & M7 & M149 & M218 & M181 & M11 & M9 & M10 & M135 & M3 & M6 & M141 & M177 & M2 & M4 & M134 & M8 & M5 & M121 & M204 & M1 \\
\hline M7 & - & - & + & + & + & - & + & + & +++ & + & + & + & - & - & - & - & - & - & + & + \\
\hline M149 & - & - & + & - & + & - & + & + & ++ & + & + & + & - & - & - & ++ & - & - & - & - \\
\hline M218 & - & + & - & + & + & + & + & + & + & - & + & - & + & - & - & + & - & - & - & - \\
\hline M181 & + & ++ & + & - & + & + & + & + & + & ++ & + & ++ & - & + & - & + & - & - & - & - \\
\hline M11 & - & + & + & + & - & + & - & + & + & ++ & + & ++ & ++ & + & - & - & - & - & ++ & + \\
\hline M9 & - & - & + & + & + & - & + & + & ++ & + & - & + & - & + & - & - & - & + & ++ & + \\
\hline M10 & + & + & + & + & + & + & + & + & + & + & + & + & - & - & - & - & - & - & - & - \\
\hline M135 & - & - & - & - & - & - & - & - & - & + & - & + & - & + & - & - & - & - & - & - \\
\hline M3 & + & + & ++ & + & - & + & ++ & ++ & - & ++ & ++ & + & ++ & - & - & - & - & - & - & - \\
\hline M6 & - & - & + & - & - & - & + & ++ & - & - & - & - & - & + & - & - & - & - & ++ & - \\
\hline M141 & - & + & + & + & + & + & + & + & - & + & - & + & + & - & - & ++ & - & + & ++ & - \\
\hline M177 & - & + & ++ & ++ & - & ++ & ++ & + & ++ & + & + & - & ++ & + & - & - & - & - & - & - \\
\hline M2 & - & - & - & - & - & - & - & - & - & - & - & - & - & - & - & - & - & ++ & - & - \\
\hline M4 & ++ & ++ & - & ++ & ++ & + & + & + & + & - & + & - & - & - & - & - & - & - & - & - \\
\hline M134 & - & + & - & ++ & - & + & + & - & + & ++ & + & + & - & - & - & + & - & - & + & - \\
\hline M8 & + & - & - & + & - & + & + & + & + & + & - & + & - & + & - & - & - & - & - & - \\
\hline M5 & - & - & - & - & - & - & - & - & - & - & ++ & ++ & - & - & ++ & - & - & + & - & - \\
\hline M121 & - & - & - & - & - & - & - & - & - & - & - & - & - & - & - & - & - & - & - & - \\
\hline M204 & - & - & + & - & - & - & - & - & - & - & - & - & - & - & - & - & - & - & - & - \\
\hline M1 & - & - & - & - & - & - & - & - & - & - & - & - & - & ++ & - & - & - & - & - & - \\
\hline
\end{tabular}

$-:$ indicate no zone of inhibition; +: represents until $5 \mathrm{~mm}$ wide zone of inhibition, ++: represents $5-10 \mathrm{~mm}$ wide zone of inhibition and +++: represents > $10 \mathrm{~mm}$ wide zone of inhibition.

data relative to the individual antagonistic tests, an autoinhibition phenomenon was also founded: M10 from F40 (Table 3) and C340 isolated from C80 and affiliated to $S$. spectabilis, C356 and C371 isolated from C120 and affiliated to Streptomyces albidochromogenes (data not shown). This action mode suggests that the activity is due to bacteriocins; ribosomally synthesized polypeptides serving to selectively kill closely related species while the producer strain remains unharmed. This phenomenon acts as a control- ling factor in the maintenance of species diversity (Baba and Schneewind, 1998; Hentschel et al., 2001; Mangano et al., 2009; Nair and Simidu, 1987).

\section{Antagonistic interaction of soil bacteria against amendments bacteria}

In vitro antagonistic interactions were investigated between bacteria isolated from control soil T (20 out of 72 isolates) and those isolated from amendments: FM ( 35 out 37 isolates) and MSWC (17 out
18 isolates). Results are illustrated in Tables 4 and 5 .

\section{Case of bacteria $T$ and FM}

Table 4 shows that all $\mathrm{T}$-isolates are active and can inhibit the growth of 1 to 30 ( 85\%) FMactinomycetes; some of them, such as T16, T32, T61 and T83 were previously unable to inhibit the growth of bacteria retrieved from the same treatment T. Also, it was founded that FM-strains belonging to Streptomycetaceae and to 
Table 2. Number of sensitive and active bacteria for each tester strain isolated from different soil treatments (soil T, soil F and soil C) in relation to their phylogenetic affiliation.

\begin{tabular}{|c|c|c|c|c|}
\hline Phylogenetic group & Isolate & Related specie & Inhibition against (no. of sensitive isolates) & Inhibited by (no. of active isolates) \\
\hline \multirow{18}{*}{ treptomycetaceae } & T60 & AY561610, Actinobacterium RG-51 & 18 & 3 \\
\hline & T27 & AB249953, S. albidochromogenes & 2 & 5 \\
\hline & T11 & AB249953, S. albidochromogenes & 6 & 4 \\
\hline & T28 & EF063499, S. venezuelae & 4 & 9 \\
\hline & T82 & AB249953, S. albidochromogenes & 11 & 6 \\
\hline & T76 & AB249953, S. albidochromogenes & 1 & 8 \\
\hline & T10 & AB249953, S. albidochromogenes & 2 & 8 \\
\hline & T61 & AB249953, S. albidochromogenes & 0 & 8 \\
\hline & T32 & AB249953, S. albidochromogenes & 0 & 5 \\
\hline & T85 & AB249953, S. albidochromogenes & 17 & 3 \\
\hline & T93 & AB249953, S. albidochromogenes & 2 & 5 \\
\hline & T48 & AB249953, S. albidochromogenes & 17 & 10 \\
\hline & T106 & DQ026647, S. exfoliatus & 0 & 4 \\
\hline & T29 & AB249921, S. spiroverticillatus & 13 & 8 \\
\hline & T79 & AB249921, S. spiroverticillatus & 14 & 9 \\
\hline & T3 & DQ026634, S. globisporus subsp. globis. & 1 & 6 \\
\hline & T83 & DQ026647, S. exfoliatus & 0 & 2 \\
\hline & T16 & DQ026647, S. exfoliatus & 0 & 8 \\
\hline \multirow[t]{2}{*}{ Unidentified } & T25 & & 8 & 9 \\
\hline & T50 & & 10 & 6 \\
\hline
\end{tabular}


Table 2. Contd.

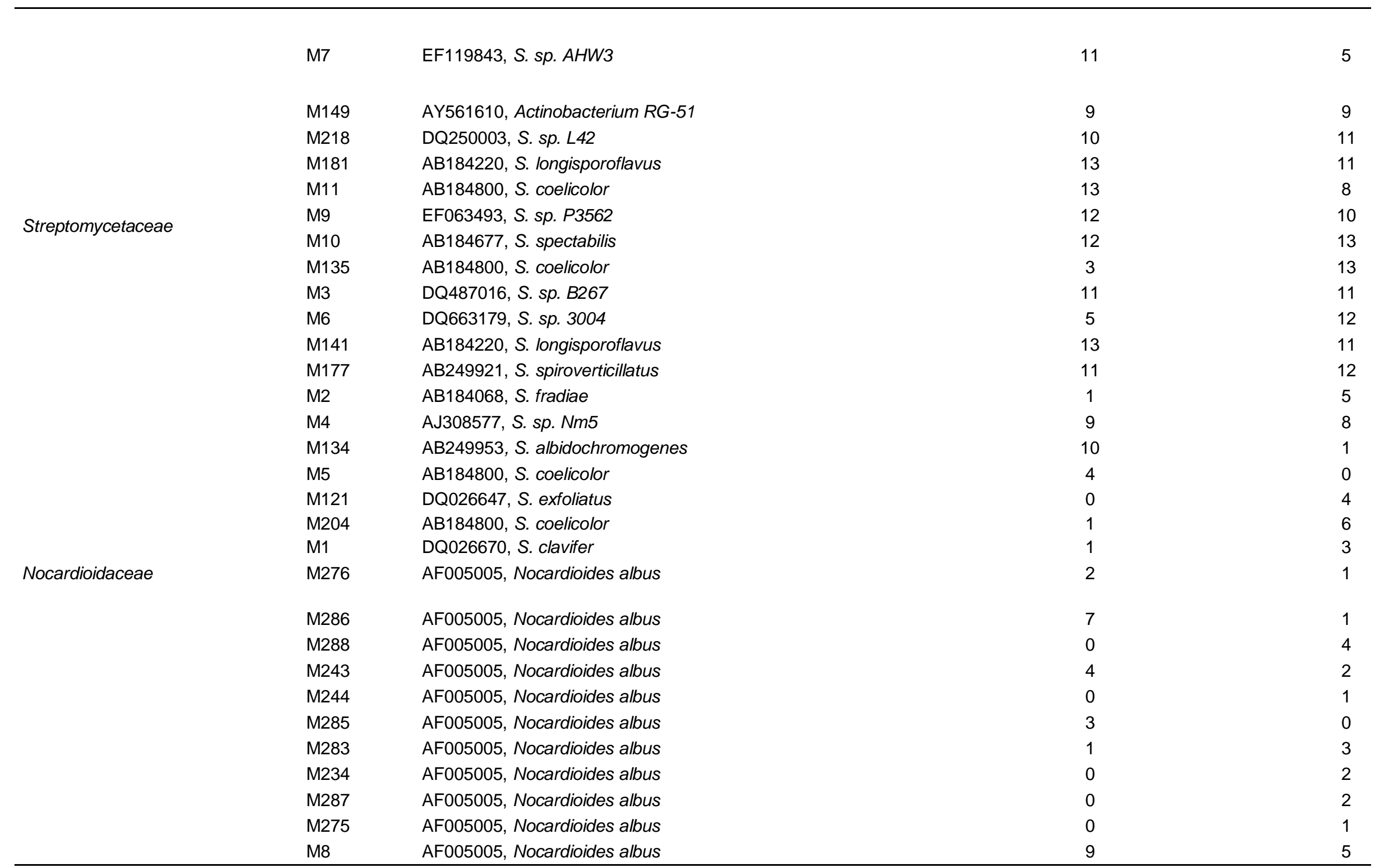


Table 2. Contd.

\begin{tabular}{|c|c|c|c|c|}
\hline & M285 & AF005005, Nocardioides albus & 3 & 0 \\
\hline & M283 & AF005005, Nocardioides albus & 1 & 3 \\
\hline & M234 & AF005005, Nocardioides albus & 0 & 2 \\
\hline & M287 & AF005005, Nocardioides albus & 0 & 2 \\
\hline & M275 & AF005005, Nocardioides albus & 0 & 1 \\
\hline & M8 & AF005005, Nocardioides albus & 9 & 5 \\
\hline & C310 & AB184393, S. spectabilis & 0 & 2 \\
\hline & C307 & AB249953, S. albidochromogenes & 0 & 2 \\
\hline & C299 & AB249953, S. albidochromogenes & 8 & 3 \\
\hline & C301 & AB184220, S. longisporoflavus & 1 & 5 \\
\hline & C292 & AB184220, S. longisporoflavus & 1 & 4 \\
\hline & C295 & AB249953, S. albidochromogenes & 5 & 2 \\
\hline & C291 & AB249953, S. albidochromogenes & 2 & 4 \\
\hline & C289 & AB249953, S. albidochromogenes & 0 & 2 \\
\hline & C326 & AB184677, S. spectabilis & 4 & 3 \\
\hline & C353 & AB184220, S. longisporoflavus & 6 & 3 \\
\hline & C340 & AB184393, S. spectabilis & 7 & 3 \\
\hline \multirow{14}{*}{ Streptomycetaceae } & C343 & AB249953, S. albidochromogenes & 8 & 3 \\
\hline & C329 & AB184220, S. longisporoflavus & 2 & 1 \\
\hline & C336 & AB184220, S. longisporoflavus & 1 & 5 \\
\hline & C344 & AB184220, S. longisporoflavus & 0 & 4 \\
\hline & C337 & AB184220, S. longisporoflavus & 6 & 3 \\
\hline & C341 & AB249953, S. albidochromogenes & 0 & 4 \\
\hline & C332 & AB184393, S. spectabilis & 0 & 5 \\
\hline & C358 & AB249953, S. albidochromogenes & 16 & 6 \\
\hline & C379 & AB249953, S. albidochromogenes & 17 & 7 \\
\hline & C372 & AB184393, S. spectabilis & 0 & 6 \\
\hline & C22 & DQ250003, S. sp. L42 & 17 & 7 \\
\hline & C357 & AB249953, S. albidochromogenes & 7 & 7 \\
\hline & C362 & AB249953, S. albidochromogenes & 19 & 2 \\
\hline & $\mathrm{C} 2$ & AB184393, S. spectabilis & 0 & 4 \\
\hline
\end{tabular}


Table 2. Contd

\begin{tabular}{|c|c|c|c|c|}
\hline & C361 & AB184393, S. spectabilis & 1 & 5 \\
\hline \multirow{3}{*}{ Unidentified } & C367 & AB184393, S. spectabilis & 0 & 5 \\
\hline & C356 & AB249953, S. albidochromogenes & 4 & 4 \\
\hline & C382 & AB184220, S. longisporoflavus & 0 & 7 \\
\hline \multirow[t]{6}{*}{ Streptomycetaceae } & C3 & DQ026671, S. cavourensis subsp. Wash. & 5 & 6 \\
\hline & C370 & AB249953, S. albidochromogenes & 11 & 3 \\
\hline & C376 & AB184220, S. longisporoflavus & 11 & 8 \\
\hline & C373 & AB184220, S. longisporoflavus & 4 & 10 \\
\hline & C371 & AB249953, S. albidochromogenes & 5 & 8 \\
\hline & C355 & AB249953, S. albidochromogenes & 3 & 7 \\
\hline \multirow{23}{*}{ Unidentified } & C298 & & 1 & 2 \\
\hline & C311 & & 9 & 1 \\
\hline & C375 & & 8 & 4 \\
\hline & C366 & & 1 & 7 \\
\hline & C381 & & 3 & 10 \\
\hline & MSWC1 & EF371429, S. aureus & 20 & 3 \\
\hline & MSWC2 & EU257256, S. sp. A528 & 12 & 1 \\
\hline & MSWC3 & EU273552, S. collinus & 4 & 3 \\
\hline & MSWC4 & AB184220, S. longisporoflavus & 15 & 1 \\
\hline & MSWC5 & AF306660, S. sacchari & 16 & 2 \\
\hline & MSWC6 & AF306660, S. sacchari & 18 & 0 \\
\hline & MSWC7 & AF306660, S. sacchari & 11 & 2 \\
\hline & MSWC8 & AF026081, S. sp. CHR28 & 15 & 3 \\
\hline & MSWC9 & DQ086264, S. sp. AB654 & 15 & 1 \\
\hline & MSWC10 & AB184220, S. longisporoflavus & 19 & 3 \\
\hline & MSWC11 & AB184676, S. griseoaurantiacus & 14 & 8 \\
\hline & MSWC12 & EF178674, S. azureus & 14 & 3 \\
\hline & MSWC14 & AF306660, S. sacchari & 17 & 2 \\
\hline & MSWC15 & AB184220, S. longisporoflavus & 9 & 0 \\
\hline & MSWC16 & EF371429, S. aureus & 8 & 2 \\
\hline & MSWC17 & AF026081, S. sp. CHR28 & 10 & 0 \\
\hline & MSWC18 & EU257256, S. sp. A528 & 0 & 3 \\
\hline & MSWC13 & & & \\
\hline
\end{tabular}


Table 2. Contd.

\begin{tabular}{|c|c|c|c|c|}
\hline \multirow[t]{27}{*}{ Streptomycetaceae } & FM1 & DQ026670, S. clavifer & 0 & 1 \\
\hline & $F M 2$ & AB249953, S. albidochromogenes & 1 & 2 \\
\hline & FM3 & DQ445791, S. cavourensis subsp. C. & 0 & 0 \\
\hline & FM4 & AB249953, S. albidochromogenes & 2 & 3 \\
\hline & FM5 & AY999837, S. californicus & 1 & 0 \\
\hline & FM7 & DQ663179, S. sp. 3004 & 1 & 0 \\
\hline & FM8 & AB184800, S. coelicolor & 0 & 0 \\
\hline & FM10 & AF306660, S. sacchari & 4 & 0 \\
\hline & FM11 & AB249953, S. albidochromogenes & 0 & 2 \\
\hline & FM12 & AY999837, S. californicus & 3 & 5 \\
\hline & FM14 & AB249953, S. albidochromogenes & 0 & 0 \\
\hline & FM15 & AB184677, S. spectabilis & 2 & 5 \\
\hline & FM16 & DQ026634, S. globisporus subsp. globis. & 6 & 3 \\
\hline & FM17 & AF306660, S. sacchari & 0 & 3 \\
\hline & FM18 & DQ445791, S. cavourensis subsp. C. & 0 & 0 \\
\hline & FM19 & AB184220, S. longisporoflavus & 0 & 4 \\
\hline & FM20 & DQ086264, S. sp. AB654 & 0 & 5 \\
\hline & FM22 & AF026081, S. sp. CHR28 & 6 & 9 \\
\hline & FM23 & AF026081, S. sp. CHR28 & 3 & 0 \\
\hline & FM24 & EU257256, S. sp. A528 & 0 & 4 \\
\hline & FM25 & EU273552, S. collinus & 0 & 5 \\
\hline & FM27 & EU273552, S. collinus & 5 & 3 \\
\hline & FM28 & AB184800, S. coelicolor & 0 & 0 \\
\hline & FM29 & DQ445791, S. cavourensis subsp. C. & 0 & 0 \\
\hline & FM30 & AY999837, S. californicus & 0 & 2 \\
\hline & FM33 & AY999837, S. californicus & 0 & 2 \\
\hline & FM34 & AY999837, S. californicus & 1 & 4 \\
\hline \multirow[t]{2}{*}{ Pseudonocardioidaceae } & $F M 9$ & EU284126, Amycolatopsis sp. WX001 & 1 & 10 \\
\hline & FM21 & EU284126, Amycolatopsis sp. WX001 & 1 & 11 \\
\hline
\end{tabular}


Table 2. Contd.

\begin{tabular}{|c|c|c|c|c|}
\hline \multirow[t]{6}{*}{ Noardioidaceae } & FM6 & AF005005, Nocardioides albus & 0 & 1 \\
\hline & FM13 & AF005005, Nocardioides albus & 0 & 0 \\
\hline & FM26 & AF005005, Nocardioides albus & 0 & 0 \\
\hline & FM31 & AF005005, Nocardioides albus & 1 & 0 \\
\hline & FM32 & AF005005, Nocardioides albus & 1 & 1 \\
\hline & FM37 & AF005005, Nocardioides albus & 0 & 0 \\
\hline \multirow[t]{2}{*}{ Unidentified } & FM35 & & & \\
\hline & FM36 & & & \\
\hline
\end{tabular}

Table 3. Antagonistic interactions among bacteria isolated from soil $F(F 40)$.

\begin{tabular}{|c|c|c|c|c|c|c|c|c|c|c|c|c|c|c|c|c|c|c|c|c|}
\hline \multirow{2}{*}{ Tester strain } & \multicolumn{20}{|c|}{ Target strain } \\
\hline & M7 & M149 & M218 & M181 & M11 & M9 & M10 & M135 & M3 & M6 & M141 & M177 & M2 & M4 & M134 & M8 & M5 & M121 & M204 & M1 \\
\hline M7 & - & - & + & + & + & - & + & + & +++ & + & + & + & - & - & - & - & - & - & + & + \\
\hline M149 & - & - & + & - & + & - & + & + & ++ & + & + & + & - & - & - & ++ & - & - & - & - \\
\hline M218 & - & + & - & + & + & + & + & + & + & - & + & - & + & - & - & + & - & - & - & - \\
\hline M181 & + & ++ & + & - & + & + & + & + & + & ++ & + & ++ & - & + & - & + & - & - & - & - \\
\hline M11 & - & + & + & + & - & + & - & + & + & ++ & + & ++ & ++ & + & - & - & - & - & ++ & + \\
\hline M9 & - & - & + & + & + & - & + & + & ++ & + & - & + & - & + & - & - & - & + & ++ & + \\
\hline M10 & + & + & + & + & + & + & + & + & + & + & + & + & - & - & - & - & - & - & - & - \\
\hline M135 & - & - & - & - & - & - & - & - & - & + & - & + & - & + & - & - & - & - & - & - \\
\hline M3 & + & + & ++ & + & - & + & ++ & ++ & - & ++ & ++ & + & ++ & - & - & - & - & - & - & - \\
\hline M6 & - & - & + & - & - & - & + & ++ & - & - & - & - & - & + & - & - & - & - & ++ & - \\
\hline M141 & - & + & + & + & + & + & + & + & - & + & - & + & + & - & - & ++ & - & + & ++ & - \\
\hline M177 & - & + & ++ & ++ & - & ++ & ++ & + & ++ & + & + & - & ++ & + & - & - & - & - & - & - \\
\hline M2 & - & - & - & - & - & - & - & - & - & - & - & - & - & - & - & - & - & ++ & - & - \\
\hline M4 & ++ & ++ & - & ++ & ++ & + & + & + & + & - & + & - & - & - & - & - & - & - & - & - \\
\hline M134 & - & + & - & ++ & - & + & + & - & + & ++ & + & + & - & - & - & + & - & - & + & - \\
\hline M8 & + & - & - & + & - & + & + & + & + & + & - & + & - & + & - & - & - & - & - & - \\
\hline M5 & - & - & - & - & - & - & - & - & - & - & ++ & ++ & - & - & ++ & - & - & + & - & - \\
\hline M121 & - & - & - & - & - & - & - & - & - & - & - & - & - & - & - & - & - & - & - & - \\
\hline M204 & - & - & + & - & - & - & - & - & - & - & - & - & - & - & - & - & - & - & - & - \\
\hline M1 & - & - & - & - & - & - & - & - & - & - & - & - & - & ++ & - & - & - & - & - & - \\
\hline
\end{tabular}

-: indicate no zone of inhibition; +: represents until $5 \mathrm{~mm}$ wide zone of inhibition, ++: represents $5-10 \mathrm{~mm}$ wide zone of inhibition and +++: represents > $10 \mathrm{~mm}$ wide zone of inhibition 
Table 4. Antagonistic interactions among bacteria isolated from soil $\mathrm{T}$ and those isolated from FM.

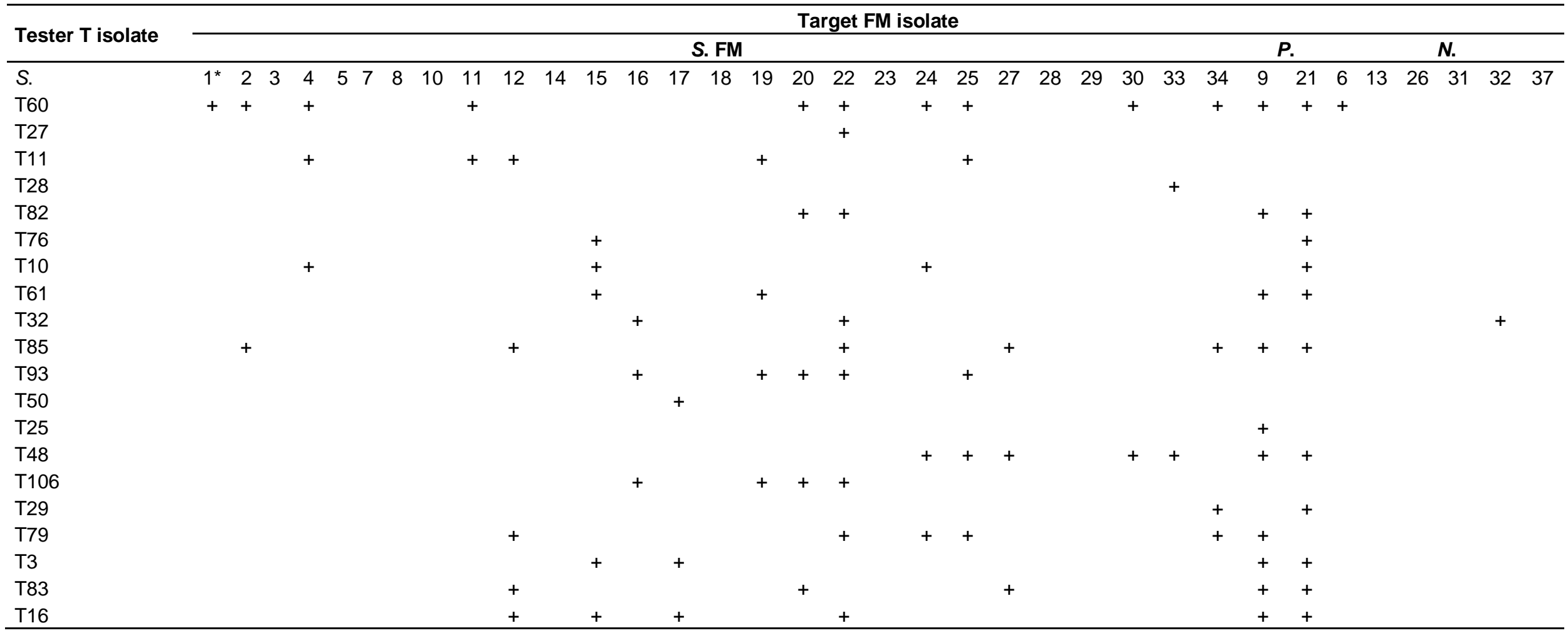

*: Number means FM number (for 1, FM1), S.: Streptomycetaceae, P.: Pseudonocardioidaceae, N.: Noardioidaceae

Pseudonocardiaceae were sensitive to 19 (95\%) and $13(65 \%)$ tester T-isolates, respectively. However, strains belonging to Nocardioidaceae, except FM6 and FM32, were resistant. For Tisolates grouped in the same OUT, they showed a slight similarity in the inhibition patterns (Table 4). This was consistent with previously founded results for antagonistic bacteria in the same treatment (data not shown). Finally, as it can be observed the majority $(55 \%)$ of sensitive FM-isolates were grouped in the same OTU (e.g. FM15 (S. spectabilis), FM20 (S. sp. AB654), FM22 (S. sp CHR28), FM24 (S. sp. A528) and FM25 (S. collinus).

\section{Case of bacteria T and MSWC}

Table 5 shows that only 13 (65\%) T-isolates were active and they inhibit the growth of 1 to $6(\sim 35 \%)$ targets; 4 from them (T3, T16, T32 and T83) were unable to inhibit the growth of bacteria retrieved from the same treatment. It was founded that $55 \%$ of MSWC-actinomycetes targets were sensitive $(76 \%)$ and that they were grouped in different OTU(e.g.MSWC7 (S. griseoaurantiacus), MSWC11 (S. sacchari)). However, T- isolates clustered in the same OTU have a difference in the inhibition patterns.

In the same way, suppressive interactions of strains isolated from FM and MSWC against Tactinomycetes were also done. It was founded that MSWC-actinomycetes inhibit a more high number of target bacteria ( 95\%) than FM isolates 
Table 5. Antagonistic interactions among bacteria isolated from soil T and those isolated from MSWC.

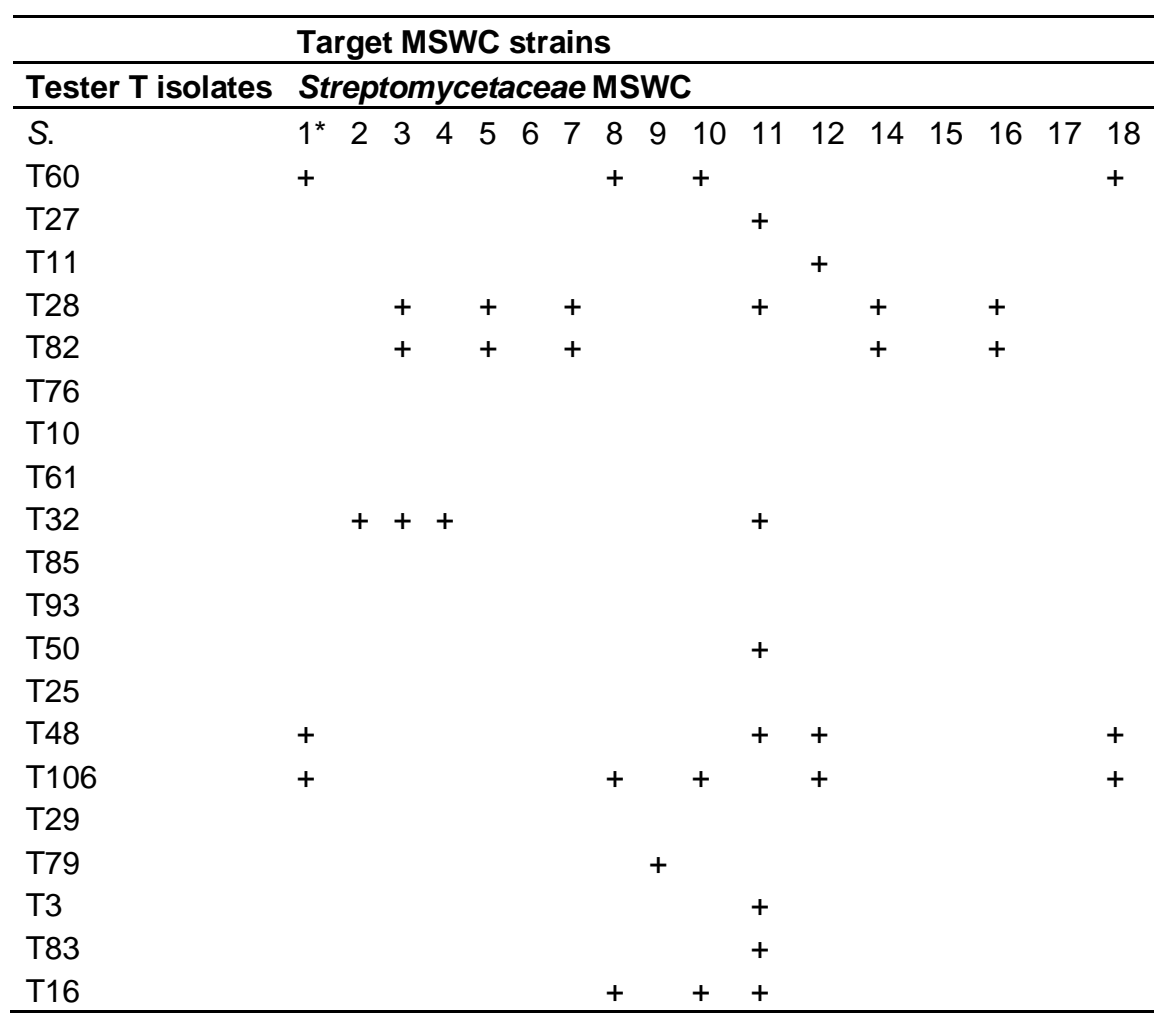

*: Number means MSWC number (for 1, MSWC1), S.: Streptomycetaceae,

shown). Above presented results show clearly that strains isolated from MSWC were more resistant and more active than those isolated from FM. Besides, it can be concluded that the amendment application can stimulat suppressive interactions of inactive bacteria of soil: e.g. T3, T16, T32 and T83. These potential antibacterial interactions of MSWC-isolates can be attributed to their high metabolic activities. Indeed, it confirms the results on assessment of enzymatic activities of actinomycetales performed in previously study (Mokni-Tlili et al., 2010; 2011b) showing that MSWC was a stimulator of enzymatic activities in soil and a potential source ofenzyme-producing bacteria. This finding was corroborated by several reports (Crecchio et al., 2004; Pascual et al. 1998; Serra-Wittling et al., 1996). Therefore, the addition of mature MSWC to soil improves soil quality, promotes plant development and reduces by antagonistic bacteria the number of diseases caused by pathogens in soil (Cotxarrera et al., 2002).

Previously (Mokni-Tlili et al., 2009), it was observed that FM was characterized by a highly actinomycetales diversity than MSWC. This was attributed to the physicochemical properties of amendments. Now, the presented results permit to attribute also this diversity variation to the antagonistic interactions between the bacteria populations. Indeed, the clustering of sensitive FMisolates in the same OTU reflected the maintaining of the Streptomycetaceae diversity in soil amended by FM but, the clustering of sensitive MSWC-isolates in different OTU reflected the decrease of genera types in soil amended by MSWC. This founded result was in agreement with those of several researchers indicating that the high genotypic and phenotypic diversity was estimated for antagonistic bacteria (Costa et al., 2006; Mangano et al., 2009). For example, Costa et al. (2006), in their investigation on the diversity and antagonistic potential of Pseudomonas ssp. in rhizosphere of maize cultivars, showed that antagonists having an enormous genotypic and functional diversity. However, homogeneous microorganism which co-inhabit in microenvironments, they have almost the similar metabolic activity which limit the antagonist reactions. Results suggest that antagonism could play a significant role in shaping bacterial communities.

\section{Antagonistic interactions between actinomycetes and tow phytopathogen bacteria}

Two phytopatogenic bacterium A. tumefaciens: C58 and B6 were tested. Figure 3 illustrates the percentage of 


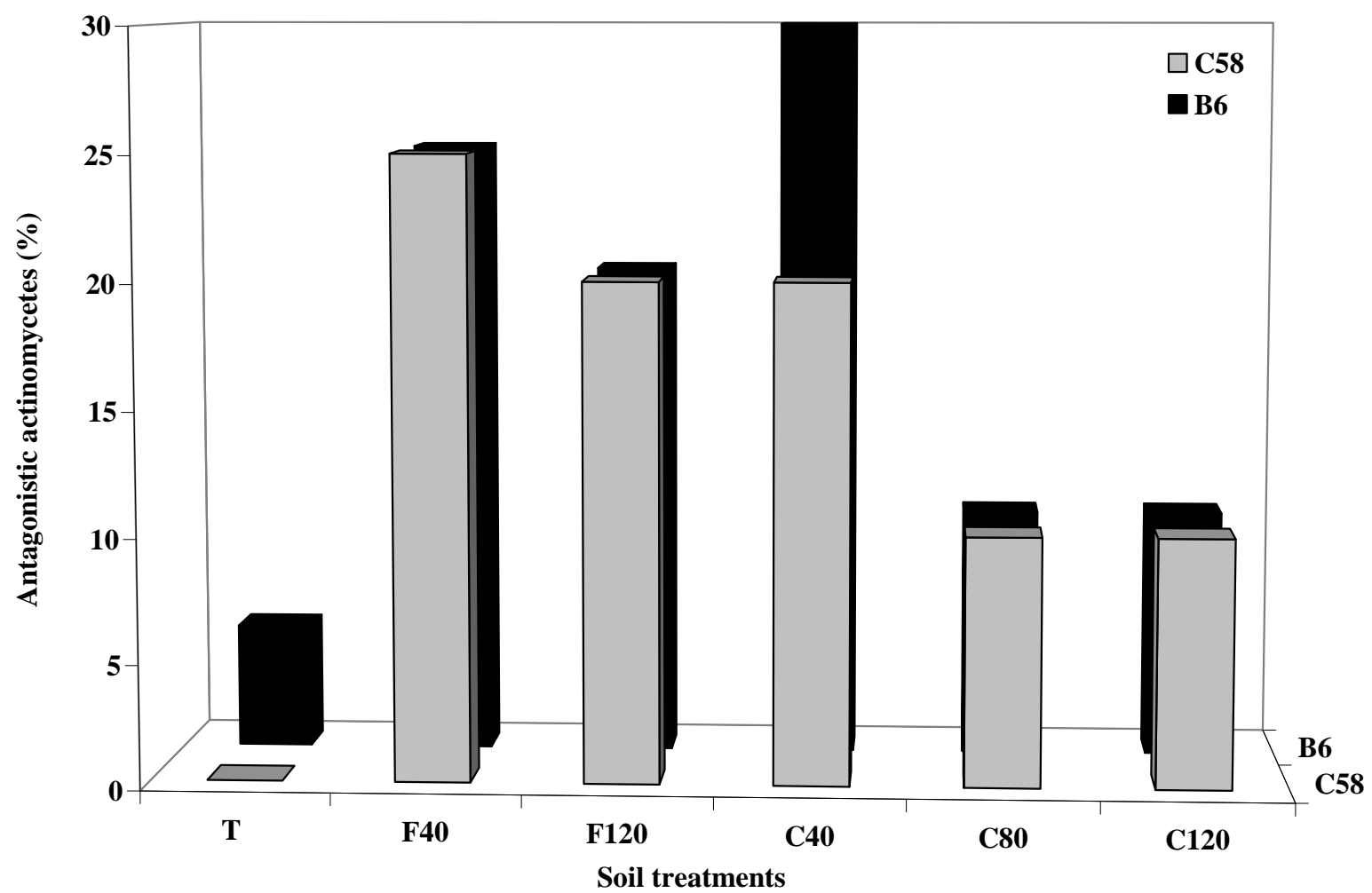

Figure 3. Antagonistic interactions among actinomycetales isolates and tow Agrobacterium tumefaciens B6 and C58.

active actinomycetales against these tow targets bacteria. They were inhibited by 10 to $30 \%$ of tester isolates. Therefore, Actinomycetales were considered among potential biocontrol agents for plant diseases producing antibiotics which can be developed for agricultural use (Tanaka and Mura, 1993). The high percentage of suppressive interactions was detected for bacteria isolated from soil F40, F120 and C40. The percentage of active bacteria was slightly decreased in soil $\mathrm{C} 80$ and $\mathrm{C} 120$. This decrease is due to the accumulation of toxic elements in these treatments (successive amendment application, one time/year for a period of 5 years) which inhibited the antibacterial activities (Mokni-Tlili et al., 2011b). For this purpose, it can be concluded that MSWC application in soil improves the soil fertility and structure.

\section{Conclusion}

At laboratory-scale, it is difficult to reproduce all biotic and abiotic features characterizing an environment, due to well-known biases arising from isolation and cultivation procedures. In fact, it must be pointed out that various environmental factors and specific soil biological and physico-chimical properties, as well as the occurrence of other kinds of microbial interactions (such as commensalism and symbiosis, which could also involve uncultiva- ble bacteria), affect the true bacterial community composition. Nevertheless, results from inhibitory assays among cultivable bacteria in artificial systems could provide precious indications on bacterial interactions occurring in a natural environment, representing a baseline for further investigation of the ecological role of soil bacteria.

In this paper antagonistic interactions among actinomycetales in soil amended or not with FM or MSWC were investigated. Based on the experimental data, the following conclusions can be made:

1. All studied treatments present a higher rate of active bacteria ( $\geq 50 \%)$.

2. The amendment application plays a double opposite roles by decreasing the antagonism and by enhancing the enzymatic synthesis and then stimulates the antimicrobial interactions.

3. Following the antagonistic interactions of bacteria and their phylogenetic affiliation studies, it can be concluded that the antagonism could play a significant role in Actinomycetales diversification.

4. The percent of antagonistic actinomycetes against $A$. tumefaciens was high for strains isolated from amended soil; this indicates that studied amendments must improve the soil fertility and structure.

5. Results from inhibitory assays suggest that antagonism could play a significant role in structuring bacterial 
communities in agricultural soil.

\section{REFERENCES}

Akhtar M, Malik A (2000). Roles of organic soil amendments and soil organisms in the biological control of plant-parasitic nematodes: a review. Bioresour. Technol. 74:35-47.

Altschul SF, Maden TL, Shaffer AA, Zhang J, Miller W, Lipman DJ (1997). Gapped BLAST and PSI-BLAST: a new generation of protein database search programs. Nucleic Acids Res. 25:3389-3402.

Baba T, Schneewind O (1998). Instruments of microbial warfare: bacteriocin synthesis, toxicity and immunity. Trends Microbiol. 6:6671.

Bensultana A, Ouhdouch Y, Hassani L, Mezrioui N, Rafouk L (2010). Isolation and characterization of wastewater sand filter Actinomycetes. World J. Microbiol. Biotechnol. 26:481-487.

Bhattarai HD, Lee YK, Cho KH, Lee HK, Shin HW (2006). The study of antagonistic interactions among pelagic bacteria: a promising way to coin environmental friendly antifouling compounds. Hydrobiologia 568:417-423

Celar F (2003). Competition for ammonium and nitrate forms of nitrogen between some phytopathogenic and antagonistic soil fungi. Biol. Control. 28:19-24.

Costa R, Salles JF, Berg G, Smalla K (2006). Cultivation independent analysis of Pseudomonas species in soil and in the rhizosphere of field-grown Verticillium dahliae host plants. Environ. Microbiol., 8: 2136-2149.

Cotxarrera L, Trillas-Gay MI, Steinberg C, Alabouvette C (2002). Use of sewage sludge compost and Trichoderma asperellum isolates to suppress Fusarium wilt of tomato. Soil Biol. Biochem. 34:467-476.

Crecchio C, Curci M, Pizzigallo MDR, Ricciuti P, Ruggiero P (2004). Effects of municipal solid waste compost amendments on soil enzyme activities and bacterial genetic diversity. Soil Biol. Biochem. 36: 1595-1605.

Duraipandiyan $\mathrm{V}$, Sasi $\mathrm{AH}$, Islam $\mathrm{VIH}$, Valanarasu $\mathrm{M}$, Ignacimuthu $\mathrm{S}$ (2010). Antimicrobial properties of actinomycetes from the soil of Himalaya. J. Mycol. Med. 20:15-20.

Epstein E (1997). The science of composting. Technomic Publishing Company, Lancaster Pennsylvania. pp. 171-211.

Fialho de Oliveira M, Germano da Silva M, Van Der Sand ST (2010).Anti-phytopathogen potential of endophytic actinobacteria isolated from tomato plants (Lycopersicon esculentum) in southern Brazil, and characterization of Streptomyces sp. R18(6), a potential biocontrol agent. Res. Microbiol. 161:565-572.

Fourati-Ben Fguira L, Fotso S, Ben Ameur-Mehdi R, Mellouli L, Laatsch $\mathrm{H}$ (2005). Purification and structure elucidation of antifungal and antibacterial activities of newly isolated Streptomyces sp. strain US80. Res. Microbiol. 156:341-347.

Gesheva V (2002). Rhizosphere microflora of some citrus as a source of antagonistic actinomycetes. Europ. J. Soil Biol. 38:85-88.

Grossart HP, Schlingloff A, Bernhard M, Simon M, Brinkhoff T (2004). Antagonistic activity of bacteria isolated from organic aggregates of the German Wadden Sea. FEMS Microbiol. Ecol. 47:387-396.

Groth I, Vettermann R, Schuetze B, Schumann P, Saiz-Jimenez C (1999). Actinomycetes in Karstic caves of Northern Spain (Altamira and Tito Bustillo). J. Microbiol. Methods 3:115-122.

Hardy GESTJ, Sivasithamparam K (1995). Antagonism of fungi and actinomycetes isolated from composted eucalyptus bark to phytophthora drechsleri in a steamed and non-steamed composted eucalyptus bark-amended container medium. Soil Biol. Biochem. 27:243-246

Hayakawa M, Ishizawa K, Nonomura H (1988). Distribution of rare actinomycetes in Japanese soils. J. Ferment. Technol. 66:367-373.

Hentschel U, Schmid M, Wagner M, Fieseler L, Gernert C, Hacker J (2001). Isolation and phylogenetic analysis of bacteria with antimicrobial activities from the Mediterranean sponges Aplysina aerophoba and Aplysina cavernicola. FEMS Microbiol. Ecol. 35:305312.
Igarashi Y (2004). Screening of novel bioactive compounds from plantassociated actinobacteria. Actinomycetologia 18:63-66.

Jayasinghe D, Parkinson D (2008). Actinomycetes as antagonists of litter decomposer fungi. Appl. soil Ecol. 38: 109-118.

Lee JL, Hwang BK (2002). Diversity of antifungal actinomycetes in various vegetative soils of Korea. Can. J. Microbiol. 48:407-417.

Li X, She Y, Sun B, Song H, Zhu Y, Lv Y, Song H (2010). Purification and characterization of a cellulase-free, thermostable xylanase from Streptomyces rameus L2001 and its biobleaching effect on wheat straw pulp. Biochem. Eng. J. 52:71-78

Lo Giudice A, Brilli M, Bruni V, De Domenico M, Fani R, Michaud L (2007). Bacterium-bacterium inhibitory interactions among psychrotrophic bacteria isolated from Antarctic seawater (Terra Nova Bay, Ross Sea). FEMS Microbiol. Ecol. 60:383-396.

Long RA, Azam F (2001). Antagonistic interactions among marine pelagic bacteria. Appl. Environ. Microbiol. 67:4975-4983.

Lumsden RD, Carter JP, Whipps JM, Lynch JM (1990). Comparison of biomass and viable measurements in the antagonism of Trichoderma harzianum against Pytium ultimum. Soil Biol. Biochem. 22:187-194.

Mangano S, Michaud L, Caruso C, Brilli M, Bruni V, Fani R, Lo Giudice A (2009). Antagonistic interactions between psychrotrophic cultivable bacteria isolated from Antarctic sponges: a preliminary analysis. Res. Microbiol. 160:27-37.

Meidute S, Demoling F, Baath E (2008). Antagonistic and synergistic effects of fungal and bacterial growth in soil after adding different carbon and nitrogen sources. Soil Biol. Biochem. 40:2334-2343.

Miyadoh S (1993). Research on antibacterial screening in Japan over the last decade: A producing microorganisms approach. Actinomycetologica 7:100-106.

Mokni-Tlili S, Ben Abdelmalek I, Jedidi N, Belghith H, Gargouri A, Abdennaceur H, Marzouki MN (2010). Exploitation of biological wastes for the production of value-added hydrolases by Streptomyces sp. MSWC1 isolated from municipal solid waste compost. Waste Manage. Res. 28:828-837.

Mokni-Tlili S, Jaoua L, Murano F, Jedidi N, Abdennaceur H (2009). Study of the effects of urban organic residues on the distribution of culturable actinomycetes in a Tunisian agricultural soil. Waste Manage. Res. 27:224-232.

Mokni-Tlili S, Jedidi N, Hassen A (2011a). Studies on the ecology of actinomycetes in an agricultural soil amended with organic residues: I. identification of the dominant groups of Actinomycetales. World J. Microbiol. Biotechnol. In press DOI 10.1007/s11274-011-0687-5.

Mokni-Tlili S, Jedidi N, Hassen A (2011b). Studies on the ecology of actinomycetes in an agricultural soil amended with organic residues: II. Assessment of enzymatic activities of Actinomycetales isolates. World J. Microbiol. Biotechnol. In press DOI 10.1007/s11274-0110688-4.

Nair S, Simidu U (1987). Distribution and significance of heterotrophic marine bacteria with antibacterial activity. Appl. Environ. Microbiol. 53:2957-2962.

Pascual JA, Hernandez T, Garcia C, Ayuso M (1998). Enzymatic activities in an arid soil amended with urban organic wastes: Laboratory experiment. Bioresour. Technol. 64:131-138.

Priscu JC, Adams EE, Lyons WB, Voytek MA, Mogk DW, Brown RL, McKay CP, Takacs CD, Welch KA, Wolf CF, Kirshtein JD, Avci R (1999). Geomicrobiology of subglacial ice above Lake Vostok. Antarctica Sci. 286:2141-2144.

Rajapaksha RMCP, Tobor-Kaplon MA, Baath E (2004). Metal toxicity affects fungal and bacterial activities in soil differently. Appl. Environ. Microbiol. 70:2966-2973.

Serra-Wittling C, Houot S, Alabouvette C (1996). Increased soil suppressiveness to Fusarium wilt of flax after addition of municipal solid waste compost. Soil Biol. Biochem. 28:1207-1214.

Suzuki K, Nagai K, Suzuki Y (1994). Search for actinomycetes in screening for new bioactive compounds. Actinomycetologica 8:122127.

Tanaka YT, Mura SO (1993). Agroactive compounds of microbial origin. Ann. Rev. Microbiol. 47:57-87.

Thompson JD, Higgins DG, Gibson TJ (1994). ClustalW: improving the sensitivity of progressive multiple sequence alignment through 
sequence weighting, position-specific gap penalties and weight matrix choice. Nucleic Acids Res. 22:4673-4680.

Tiquia SM, Wan JHC, Tam NFY (2002). Microbial Population Dynamics and Enzyme Activities during Composting. Compost. Sci. Utilisation 10:150-161.

Tobor-Kaplon MA, Bloem J, Romkens PFAM, de Ruiter PC (2005). Functional stability of microbial communities in contaminated soils. Oikos 111:119-129.
Vaneechoutte M, Rossau R, De Vos P, Gillis M, Janssens D, Paepe N, De Rouck A, Fiers T, Claeys G, Kerster K (1992). Rapid identification of bacteria of the Comamonadaceae with amplified ribosomal DNArestriction analysis (ARDRA). FEMS Microbiol. Lett. 93:227-234.

Yuan WM, Crawford D (1995). Characterization of Streptomyces lydicus WYE108 as potential biocontrol agent against fungal root and seed rots. Appl. Environ. Microbiol. 61:3119-3128. 